\section{Bioética da proteção e tratamento de doenças genéticas raras no Brasil: o caso das doenças de depósito lisossomal}

\author{
Principle of protection and treatment of rare \\ genetic diseases in Brazil: the case of lysosomal \\ storage disorders
}

Raquel Boy ${ }^{1}$

Fermin Roland Schramm ${ }^{2}$

\section{Introdução}

This study aimed to discuss the morality of public funding for highly expensive orphan drugs for treatment of rare genetic diseases, using tools from bioethics, especially the principle of protection, applicable to vulnerable individuals and populations. Based on this principle, and considering the provisions of the Unified National Health System (SUS), the article argues for the state's moral obligation to provide public policies to ensure care for individuals with genetic diseases like lysosomal storage disorders, who can thus be viewed as "injured", besides suggesting measures to implement and ensure the sustainability of policies with an emphasis on resource allocation, targeting, and equity.

Lysossomal Storage Diseases; Exceptional Drugs; Bioethics
Com os progressos biotecnocientíficos obtidos nas pesquisas farmacêuticas, medicamentos para o tratamento de doenças raras estão sendo paulatinamente inseridos no cenário mundial sob aprovação de governos americanos e europeus. Apesar de não haver uma definição única para estas doenças, elas podem ser entendidas, de acordo com critérios europeus, como doenças cuja incidência seja inferior a 5 por $10 \mathrm{mil}$ habitantes e que preencham as seguintes características clínicas: serem crônicas, degenerativas, debilitantes e associadas à diminuição da expectativa de vida. Embora individualmente raras, somam-se cerca de 6 mil doenças que afetam cerca de 55 milhões de pessoas na União Européia e Estados Unidos 1,2,3.

Se levarmos em conta estas estimativas e extrapolarmos para estatísticas populacionais brasileiras, é provável que estejamos discutindo acerca da existência também de milhões de brasileiros com alguma doença genética, com um percentual crescente que demandará acesso aos tratamentos já disponibilizados, muitos deles pelo fornecimento de medicamentos especiais, alguns destes conhecidos como drogas órfãs.

Ainda que algumas dessas drogas órfãs já estejam sendo comercializadas na União Européia, nos Estados Unidos, Austrália e em alguns países asiáticos 3, poucas são as medicações para o tratamento de doenças raras que foram incluídas 
na lista de medicamentos excepcionais do Ministério da Saúde, mediante portarias especiais 4,5 . Dentre tais medicações citamos a imiglucerase, para o tratamento da doença de Gaucher, uma condição rara, pertencente ao grupo das doenças de depósito lisossomal (DDL).

Dessa forma, muitos pacientes no Brasil vêm buscando o acesso a esses medicamentos, incluindo aqueles voltados para o tratamento das DDL, ainda não acrescentadas na lista de medicamentos excepcionais por intermédio de medidas judiciais (judicialização). Tais medidas nem sempre são favoráveis aos seus pleiteadores, em razão, sobretudo, do custo elevado do tratamento e as suas implicações orçamentárias. Nesse cenário, surgem conflitos éticos importantes, referentes às políticas sanitárias de acesso aos recursos necessários para o tratamento das doenças raras no Brasil, mas são ainda pouco discutidas as maneiras possíveis e desejáveis, capazes de resolver os conflitos.

Este trabalho tem por objetivo descrever os conflitos éticos gerados no âmbito da saúde pública quanto ao tratamento de DDL, à luz das ferramentas da Bioética, utilizando o Princípio da Proteção desenvolvido por Schramm \& Kottow 6 .

\section{Aspectos referentes às doenças de depósito lisossômico}

As DDL constituem importante grupo de doenças genéticas, raras individualmente, mas que, quando somadas, respondem por uma prevalência de 1:7.700 nascimentos. Elas representam um grupo de, pelo menos, 50 entidades genéticas distintas, cada uma delas resultante de deficiência de uma atividade protéica particular, ou, excepcionalmente, de atividades não lisossomais que estão envolvidas na biogênese da maturação protéica. O número de DDL está aumentando à medida que novas doenças são caracterizadas do ponto de vista genético e bioquímico. Mesmo que cada uma das DDL seja decorrente de mutações em genes diferentes e, conseqüentemente, em uma deficiência enzimática específica, todas as DDL compartilham uma característica comum: o acúmulo de substratos normalmente degradados nos lisossomos. De acordo com o tipo de substrato acumulado, as DDL são agrupadas em amplas categorias, incluindo as mucopolissacaridoses, as lipidoses, as glicogenoses e as oligossacaridoses. Estas categorias mostram similaridades clínicas que incluem: anormalidades ósseas, organomegalia, disfunção do sistema nervoso central em algumas formas e dismorfias craniofaciais de caráter cumulativo, levando, em sua maioria, a comprometimento sistêmico grave e diminuição importante da expectativa de vida.

Existem diferentes estratégias de tratamento para as DDL; dentre elas: a terapia de reposição enzimática (TRE), que vem se mostrando benéfica para o tratamento da doença de Gaucher em sua forma não neuronopática há mais de 15 anos.

A doença de Gaucher é a DDL mais comum, caracterizada pelo acúmulo de uma substância no sistema retículo-endotelial, devido a uma deficiência enzimática específica. Sua história natural, previamente ao uso da medicação, revelava o aparecimento precoce de esplenomegalia, pancitopenia, hepatomegalia, dor óssea e fraturas, cujos quadros mais graves levavam ao falecimento do paciente entre a primeira e a segunda década de vida.

Os resultados da TRE têm sido positivos, com melhora na maioria das patologias para as quais este tipo de terapia se encontra disponível, sem o mesmo sucesso, no entanto, para o tratamento de sintomas neurológicos. Para as formas que apresentam sintomas neuropatológicos, estão sendo avaliadas outras formas de terapia, como o transplante de medula óssea, o uso de redução de substratos e o uso de pequenas moléculas. A TRE tem sido também disponibilizada para o tratamento de outras DDL, como a doença de Fabry, MPS I, MPS VI e, recentemente, MPSII e doença de Pompe 7,8 .

\section{Aspectos referentes às drogas órfãs}

Estão sendo produzidas medicações que atendem a portadores de duas categorias principais de doenças no mundo: as doenças raras - genéticas em sua maioria - e as doenças tropicais. Tais medicações são denominadas drogas órfãs, pois habitualmente não são desenvolvidos por indústrias farmacêuticas, essencialmente por dois motivos econômicos: condição muito rara para representar um mercado considerado rentável, ou condição que seria prevalente em países em desenvolvimento, os quais seriam pobres demais para pagarem pelo preço dos medicamentos e garantir o lucro para os detentores de patentes 9 . Entretanto, visando estimular a investigação e o desenvolvimento de medicamentos órfãos, autoridades de países desenvolvidos implementaram, mediante políticas mundiais, incentivos paras as indústrias de biotecnologia 9,10. As medidas tiveram início em 1983 nos Estados Unidos com a criação do Orphan Drug Act, seguido pelo Japão em 1993, Austrália em 1997, e a União Européia, que criou uma política comum para os medicamentos órfãos em 1999 3,9. 
Tendo em vista os altos valores alocados para o desenvolvimento de pesquisas e a disponibilização do tratamento das doenças genéticas raras, aspectos éticos e econômicos têm sido discutidos no contexto das sociedades desenvolvidas. De um lado, questões que vão desde a moralidade do financiamento de pesquisas em drogas órfãs até a análise de critérios para aquisição de medicamento especial e o impacto no orçamento. E, do outro lado, questões sobre as formas de financiamento/reembolso do tratamento no nível de sistema de saúde vigente e das maneiras de diminuir as iniqüidades geográficas na distribuição dos medicamentos para garantir o acesso ao tratamento, também têm sido discutidas 9,10,11.

No entanto, dificuldades na avaliação da efetividade clínica, para a qual outros tratamentos ainda não existem, também já são relatadas, o que faz crescer a discussão acerca da disponibilização e o conseqüente custo do tratamento $9,10,11$.

Observa-se, de uma forma geral - e em função do status de medicação especial e efetividade terapêutica em algumas das DDL, como a doença de Gaucher e a doença de Fabry - um posicionamento favorável, ainda que cauteloso, em relação ao financiamento público das medicações para o tratamento destas doenças, apesar dos altíssimos custos 11 .

\section{Tratamento de doenças genéticas no Brasil: o caso da doença de Gaucher}

A doença de Gaucher tipo I foi a primeira doença genética a ser contemplada para a TRE com o medicamento imiglucerase, que interrompeu o curso natural da doença, permitindo aos pacientes - quando submetidos ao tratamento - uma vida normal e produtiva. Este medicamento está sendo oferecido pela União e foi incluído na Relação de Medicamentos Excepcionais, desde 1995 4. Tal fato ocorreu após alguns anos de intensa movimentação da Associação Brasileira de Portadores de Doença de Gaucher para o acesso e a obtenção do medicamento, que era feito antes, mediante ações judiciais e lobbies buscando destacar as necessidades do grupo de portadores desta doença junto aos poderes Legislativo e/ou Executivo por parte das famílias dos portadores. Os gastos com o Programa de Medicamentos Excepcionais custou, em 2005, aproximadamente R\$ 1,2 bilhão. Quatorze medicamentos são responsáveis por $60 \%$ de seu custo. Entre eles, inclui-se a imiglucerase, que é uma das principais responsáveis por estes custos 12 .
O progresso biotecnocientífico continua e, com ele, a disponibilidade crescente para tratamento de outras doenças genéticas raras. Este fato vem trazendo consigo novamente problemas já enfrentados por pacientes, familiares, gestores de saúde no âmbito dessas doenças: drogas únicas; custos elevados e direcionados ao tratamento de um número proporcionalmente pequeno de pacientes; e não liberadas pelo governo brasileiro para utilização via política pública de saúde. Com efeito, a via de obtenção atual para estes medicamentos tem sido, na maioria dos casos, as medidas judiciais - nem sempre atendidas -, utilizando os preceitos da Constituição Federal de 1988: " a saúde é direito de todos e dever do Estado, garantindo mediante políticas sociais e econômicas que visem à redução do risco de doença e de outros agravos e ao acesso universal e igualitário às ações e serviços para sua promoção, proteção e recuperação", recaindo sobre o Estado o dever de garantir a universalidade, a integralidade e a eqüidade no tratamento e na assistência, garantidos pelo Sistema Único de Saúde (SUS)

O SUS, todavia, vem enfrentando desafios crescentes conforme discutido no Fórum da Reforma Sanitária Brasileira 13. Apesar dos reconhecidos avanços na produção, produtividade e inclusão, pouco se avançou na efetivação da integralidade da assistência e da eqüidade no acesso. Isso constitui um problema bioético relevante, pois a simultaneidade de avanços na compreensão e no tratamento das causas das doenças (favorecendo a incorporação de novos procedimentos diagnósticos e terapêuticos) e a vigência da "cultura dos limites" (selecionando tais procedimentos por questões orçamentárias) representam um grande desafio de justiça sanitária para os gestores de saúde, instados, por um lado, pelas demandas legítimas e crescentes dos usuários, e, por outro, pela urgência de "racionalizar" em termos pragmáticos os recursos efetivamente disponíveis, considerados escassos 14. Entretanto, é importante contextualizar tal "racionalização", lembrando os baixos recursos públicos brasileiros destinados aos gastos com saúde, seja em percentuais em relação ao produto interno bruto (cerca de 3\%), seja em relação ao custo per capita (entre US\$ 120 e US\$150), fato que representa cerca de $10 \%$ a menos do que o gasto nos países europeus e no Canadá 15 . Tendo em conta simultaneamente as considerações orçamentárias e as considerações éticas referentes à justiça distributiva, a crise sanitária vigente implicaria um dilema aparentemente sem solução: os sistemas de saúde com vocação universalista, não podendo incorporar despesas indefinidamente e, ao mesmo tempo, não podendo ignorar a sua vocação universalista fundamentada na integralidade da 
atenção médico-hospitalar, especialmente para não perder sua identidade e legitimidade moral, visto que ela constitui uma das três diretrizes fundamentais do SUS, garantida por lei 16 .

Diante destas questões, tornar-se-ia um problema complexo a alocação de recursos, demandando discussão em que sejam levados em conta os aspectos sanitários, econômicos, políticos e morais. Nesse contexto, utilizamos as ferramentas da bioética, que se preocupa em avaliar simultaneamente, de forma racional e imparcial, os argumentos a favor e contrários a uma determinada decisão, e em colocar em prática a solução considerada moralmente mais legítima.

Discutiremos, pois, algumas questões a favor e contra o Estado assumir o tratamento de doenças raras como as DDL, na tentativa de viabilizar medidas que possam beneficiar seus portadores, em nome da integralidade e da eqüidade, sem, com isso, desrespeitar a universalidade, pois os princípios do SUS devem ser considerados juntos, por mais que possam existir tensões entre eles nos casos concretos. Para tanto, será utilizado o Princípio da Proteção, desenvolvido no âmbito da bioética latino-americana 6 .

\section{Princípio da Proteção}

Na tentativa de dar conta das controvérsias morais no âmbito da saúde pública que se referem a populações de suscetíveis ou vulnerados - isto é, ameaçados (os suscetíveis) ou afetados (os vulnerados) em sua saúde - Schramm \& Kottow 6 propõem a utilização do Princípio da Proteção. Consideram-no mais adequado que o tradicional modelo principialista, desenvolvido por Beauchamp \& Childress 17, baseado no modelo dos princípios de não maleficência, beneficência, autonomia e justiça, e amplamente usado em bioética entre os anos 70 e meados dos anos 90 do século XX. Destacam que o principialismo éinsuficiente para enfrentar as carências e a flagrante injustiça social nos países em desenvolvimento, vale dizer, nas situações de empoderamento escasso; devendo, portanto, ser substituído por uma bioética da proteção, capaz de dar conta da realidade das sociedades latino-americanas, nas quais seus cidadãos sofrem discriminações, assimetrias e desigualdades gritantes.

O Princípio da Proteção constitui um dos fundamentos da intervenção do Estado, que reconhece sua obrigação de cuidar da integridade física e patrimonial de seus cidadãos a partir do século XVIII, sendo também o fundamento moral da legitimidade do Estado de bem-estar contemporâneo. Com base neste princípio, a bioética de proteção pode ser vista como uma ética da responsabilidade social em que o Estado deve assumir obrigações que se aplicam às populações humanas, visando prevenir suas enfermidades e formar um ambiente saudável, com propostas razoáveis de cuidar das condições objetivas necessárias para o exercício da cidadania. Entendendo-se, então, como proteção a atitude de dar cobertura efetiva às necessidades essenciais ou consideradas impostergáveis.

Mas, para os fins de nossa discussão sobre os portadores de DDL, cabe, aqui, uma observação crítica sobre a categoria guarda-chuva de proteção, distinguindo os termos vulnerabilidade e vulneração. Aplica-se o conceito de vulnerabilidade à condição existencial humana enquanto tal, a saber, a uma característica universal e genérica de qualquer ser vivo, inclusive humano. Já o conceito de vulneração se aplica à condição existencial específica de seres ou populações particulares que, nas contingências adversas independentes de suas vontades, não possuem os meios necessários (ou capacidades) para enfrentá-las. Por isso, não é a vulnerabilidade, mas a vulneração que constituiria o objeto da proteção. A bioética da proteção distingue, ainda, uma terceira categoria intermediária: a suscetibilidade, que se aplica, por exemplo, aos portadores de doenças de origem genética, que são "suscetíveis" porque a doença pode se manifestar, tornando-os, assim, vulnerados. Logo, a vulnerabilidade é da ordem do risco de viver, ao passo que a suscetibilidade e, a fortiori, a vulneração pertencem a situações de fato 18 . Concretamente, quando um ser humano sofre de alguma incapacidade - debilidade, enfermidade, deficiências físicas incapacitantes -, deixa de ser meramente vulnerável e se converte em "vulnerado", requerendo ações de proteção terapêutica 19. No caso específico das doenças genéticas, em muitas delas existe, além da suscetibilidade que a caracteriza, uma condição de vulneração já instalada. Esta fará com que o indivíduo desenvolva em algum momento da sua vida - desde intra-útero até a idade adulta - um dano efetivo sobre a sua saúde, que é uma efetiva vulneração. O Princípio da Proteção se aplica especificamente a estes indivíduos que se situam numa faixa de suscetíveis até vulnerados, e que, por causa da esta condição existencial particular e considerada desfavorável, não estão em condições de exercerem plenamente sua autonomia nas tomadas de decisão que dizem respeito à sua saúde e bem-estar 18 . Nesse caso, trata-se de portadores de enfermidades requerendo ações de proteção terapêutica que devem estar disponíveis e acessíveis, de acordo com a função protetora do Estado, garantia dos direitos do cidadão 19 . 
Por sua vez, a proteção dos vulnerados aplicada a políticas públicas legítimas relaciona-se com o princípio da eqüidade, que implica medidas de focalização de ações sociais a favor dos mais necessitados (suscetíveis, vulnerados). Por exemplo, a implementação de políticas focalizadas em áreas específicas das políticas públicas de atenção à saúde, sobretudo em situações de escassez de recursos, pode - como relatado por Ribeiro \& Schramm 20 - ser necessária, inclusive adotando medidas compensatórias para poder superar as desigualdades existentes e alcançar efetivamente a igualdade de todos, defendida pela Constituição Federal brasileira. Para tal, a focalização se aplicaria tanto às condições pessoais quanto às condições sócio-econômicas dos indivíduos e grupos sociais vulnerados. Sendo assim, as tecnologias médicas avançadas seriam oferecidas não somente em função das necessidades médicas dos pacientes - que podem eventualmente ter os meios para satisfazê-las -, mas também em função dos recursos de que eles dispõem para adquiri-las, parcial ou totalmente. Em suma, na proteção busca-se o equilíbrio entre uma concepção de justiça, que condena as discriminações e favorece a igualdade, e uma concepção que visa compensar os efeitos moralmente problemáticos da primeira, e resultantes do fato das desigualdades de fato existentes, privilegiando, para tanto, as ações focais a favor dos mais necessitados, em busca da equanimidade 19. Porém, para evitar equívocos - como aquele que confunde o princípio de proteção com o tradicional paternalismo -, deve-se ressaltar que a proteção só é legítima até que suscetíveis e vulnerados adquiram a competência de exercer sua autonomia ou a recuperem 21 .

Para finalizar, as ações devidas pelo Estado aos pacientes suscetíveis ou vulnerados - e que são constitutivas de sua prática de proteção - não estão desvinculadas do dever de eficácia, pois esta é uma condição para poder intervir legitimamente na vida dos cidadãos 22. Dessa forma, a responsabilidade protetora implicaria necessariamente no controle dos resultados das políticas públicas adotadas, com avaliação da eficácia e da efetividade das práticas das instituições públicas e de seus gestores. Avaliando, também, os efeitos positivos prováveis, resultantes da incorporação de Ciência e Tecnologia em ações "protetoras" de saúde. Assim sendo, ao integrar a responsabilidade moral e a eficácia pragmática numa efetiva política sanitária protetora, podem-se legitimar políticas sanitárias que se pretendem universalistas do ponto de vista dos valores - a exemplo da política sanitária inspirada na Constituição Federal brasileira e nos princípios do SUS - devendo, no entanto, enfrentar também a questão de que nem todos têm o mesmo tipo de necessidades nem as mesmas condições iniciais para enfrentar seus problemas de saúde. Isso traz à tona o problema da igualdade e de seus corretivos concretos que se tornam moralmente justificáveis, fazendo referência ao princípio moral da eqüidade, o qual, em substância, implica adotar políticas compensatórias capazes de garantir a igualdade formal em termos concretos.

\section{Argumentos favoráveis e contrários à assistência}

Se aceitarmos que o Princípio de Proteção é válido para justificar o amparo de suscetíveis e vulnerados, poder-se-ia, por outro lado, dizer que, como o tratamento está disponível e é comprovadamente eficaz, bastaria aplicar o Princípio da Beneficência, cuja obrigação moral envolvida é a do não-abandono da pessoa à própria sorte ou regra do resgate ("rule of rescue") 23. Contudo, trata-se, aqui, de uma confusão conceitual entre "proteger" e "beneficiar", pois - de acordo com a justificativa do Princípio de Proteção - só se pode oferecer proteção a quem não tenha capacidade de se proteger sozinho, ao passo que se pode beneficiar qualquer um, vulnerado, suscetível ou simplesmente vulnerável. O mesmo tipo de consideração vale, mutatis mutandis, para o Princípio de Não-maleficência. Porém, no caso específico dos portadores de DDL, os atos de proteger e de beneficiar são muito próximos, uma vez que os primeiros podem ser vistos como uma forma de beneficiar suscetíveis e vulnerados, embora se possa beneficiar alguém que não tenha a necessidade de ser protegido.

De fato, o Princípio de Proteção tem uma proximidade conceitual com o Princípio da Eqüidade, segundo o qual os indivíduos são diferentes entre si e, portanto, merecem tratamento diferenciado que elimine (ou reduza) a desigualdade. O Princípio de Eqüidade referese, assim, a uma concepção compensatória de justiça, aplicada à desigualdade de fato, visando eliminá-la. Em outros termos, o critério para a justiça na desigualdade é aquele assumido pela concepção de justiça que considera que o tratamento desigual é justo quando é benéfico ao indivíduo mais carente 19. A proteção dos suscetíveis e vulnerados, como são os portadores de DDL, é um desses casos.

Mas haveria, também, alguns argumentos contrários ao Estado assumir determinados tratamentos, especialmente se considerarmos os custos crescentes e a finitude e carência de recursos da União, e sua apropriada ou justa alocação. O principal argumento é de tipo uti- 
litarista, segundo o qual seria antiético investir somas substanciosas de recursos para condições raras e para poucos: custos elevados beneficiando um pequeno número de pacientes, não maximizando os benefícios para a sociedade ${ }^{17}$. Isso se aplicaria, em particular, às sociedades ditas em desenvolvimento, em que existem problemas igualmente graves que atingem um número maior de pessoas, como, por exemplo, as doenças tropicais, também conhecidas como doenças negligenciadas.

Outro argumento seria aquele do enfraquecimento do poder dos Estados Nacionais frente a uma rede difusa de poderes dominada pelo capital financeiro e o mercado, ambos de caráter transnacional, que os torna voláteis e incontroláveis ${ }^{22}$. Ademais, a crescente pressão da indústria farmacêutica transnacional sobre os Estados, gerando diversos conflitos de interesse, deve ser enfrentada por um Estado capaz de avaliar pragmaticamente a eficácia/efetividade das novas medicações, promovendo políticas assistenciais e de proteção efetivas.

Críticos da equação finitude/escassez/priorização lembram que o acesso aos cuidados à saúde é um direito constitucional, havendo uma obrigação dos responsáveis por políticas públicas, eleitos pelos cidadãos para representar seus interesses e direitos, de prover os meios adequados para satisfazer as necessidades de saúde 14 . E, mesmo que se admita a pertinência do argumento da escassez de recursos, ela não poderia ser priorizada, porque não se poderia atribuir um valor à vida, ou à sua qualidade, razão pela qual a comparação seria ilegítima (Oshickle, 1998, apud Schramm 14).

\section{Conclusões}

Pelo exposto, existem argumentos favoráveis e contrários à assistência sanitária a doenças genéticas raras, mas, como tentamos mostrar pela aplicação do principio bioético de proteção nas situações de populações de suscetíveis e vulnerados, justificam-se políticas focais que os privilegiam em face da população meramente vulnerável. Entretanto, a prioridade léxica atribuída, neste caso, à eqüidade levanta uma série de problemas, sendo o principal aquele referente ao princípio da universalidade, que parece ser contradito no caso da focalização. Vimos também que o próprio princípio de justiça pode ser entendido não como uma genérica e abstrata igualdade, mas como eqüidade, que implica políticas compensatórias que privilegiam suscetíveis e vulnerados para se chegar pelo menos a uma redução da desigualdade prévia. No caso dos portadores de DDL, os princípios de proteção e de eqüidade implicam a inclusão de drogas órfãs na lista de medicamentos excepcionais, mediante elaboração de protocolos clínicos e diretrizes terapêuticas, periodicamente revisados.

Quais seriam as outras opções? Negar o tratamento? Reduzir as doses? Limitar o acesso? Firmar parcerias com fundos de financiamento? Desenvolver tecnologias que permitam a produção interna, com conseqüente redução dos custos para o fornecimento desses medicamentos ao usuário do SUS, seria factível? Esta última proposta, no entanto, poderá tornar-se um grande desafio, tendo em vista o alto custo de desenvolvimento e implantação desta biotecnologia.

A participação do Estado na oferta e na administração do acesso à população portadora de doenças de depósito lisossômico a medicações que mostrem efetividade no seu controle, sem dúvida faz parte de uma sistemática de assistência em doenças genéticas da qual o mesmo não deve isentar-se, caso contrário estaria desrespeitando seus preceitos constitucionais e pondo em risco sua credibilidade. Neste contexto, trazemos à luz uma discussão maior, não somente acerca de questões de assistência terapêutica - de ordem de prevenção terciária das doenças genéticas -, mas questões, também, de abordagem da assistência primária e secundária de tais doenças.

Tais discussões mostram de forma premente e clara a necessidade de colaboração entre profissionais da Genética e da Saúde Pública, numa abordagem diferente da observada no século XIX e início do século XX, na qual práticas eugenicistas e daninhas foram amplamente aplicadas nas sociedades européias e americanas. Certamente, questões como eugenia, reducionismo e determinismo genéticos, alocação de recursos, discriminação, demandas comerciais, compreensão e educação dos distúrbios genéticos deverão pertencer à pauta única de discussão partilhada por bioeticistas, geneticistas e profissionais da saúde pública, conforme recentemente relatado acerca da abordagem multidisciplinar na compreensão, prevenção e tratamento de algumas doenças complexas como diabetes, demência, cardiopatia congênita e câncer 24 . Para tanto, as autoridades devem assumir, para o cuidado com a saúde das populações suscetíveis e vulneradas, programas de saúde coletiva em que se inclua a implantação de redes estruturadas de serviços de Genética Médica e Aconselhamento, atualmente extremamente restritos em termos de quantidade, distribuição geográfica (concentrados no eixo sul-sudeste) e oferta de serviços, com conseqüente limitação grave ao acesso pela população 25 . 
Neste contexto, estratégias para prevenção de novos casos devem ser discutidas, considerando ser a prevenção uma das possibilidades de estabilização dos custos crescentes dos tratamentos. Por sua vez, problemas éticos como o acesso à privacidade dos portadores de doenças genéticas e à possível interferência no exercício da autonomia do cidadão com relação a questões de diagnóstico pré-natal, interrupção de gestação e estigmatizações deverão ser aborda$\operatorname{dos} 26$.

Em particular, formas de transferência de responsabilidade devem ser discutidas, como a promoção de parcerias público-privado via participação dos seguros-saúde ou de fundações. De fato, na falta de atuação satisfatória do Estado, como no caso das doenças órfãs, há parcelas sociais que lutam para assumir a responsabilidade de proteger os suscetíveis e vulnerados: a saúde pública em interação com a Genética Médica; a sociedade civil e os grupos de autoajuda. No entanto, mesmo que o Estado não assuma inteiramente a realização das práticas em saúde e, portanto, seu papel protetor, seria inconcebível que não houvesse ao menos uma fiscalização eficiente por parte do governo central 19. Em relação ao papel da sociedade civil e aos grupos de auto-ajuda, observou-se que na inclusão de medicamentos na lista padronizada e a conseqüente compra de fármacos pelo governo, a participação das associações foi e tem sido essencial, a exemplo do ocorrido com a doença de Gaucher. Por conseguinte, a participação de associações de pais e pacientes portadores de doenças genéticas, nas discussões sobre a formulação e implementação de políticas referentes aos medicamentos excepcionais, deve ser estimulada, de acordo com os próprios princípios do SUS, do controle e da participação social.

Por sua vez, a criação de fundos de financiamento de tratamento para pacientes com doenças raras, valendo-se de ensaios clínicos, pode ser justificada em nome do interesse do avanço científico e da promoção da saúde, bem como a manutenção de comissões dedicadas a tarefas específicas como a contínua revisão de critérios metodológicos de avaliação da efetividade das medicações, que estão sendo paulatinamente ofertadas pelos laboratórios. Ademais, dado o número amostral de pacientes ser muito pequeno (por conta da raridade da condição e dificuldade diagnóstica) e a demanda de avaliações ser em curto prazo - pelo caráter progressivo da doença-, estas comissões se mostram necessárias. Com efeito, pesquisas têm mostrado o benefício das medicações para algumas das DDL, especialmente se tratadas precocemente ou voltadas para grupos específicos destes pacientes 27,28 . Além disto, critérios clínicos de inclusão e exclusão de pacientes ao tratamento também devem ser definidos e continuamente revistos, visto que as medicações disponíveis não têm apresentado redução favorável dos danos neurológicos já instalados nos casos das formas neuronopáticas de algumas das DDL 29.

Todavia, essas são medidas coadjuvantes, que podem servir para compensar as carências na atuação do Estado, de acordo com os princípios norteadores do SUS.

O aprofundamento de tais questões sem dúvida trará à baila discussões que andam adormecidas no âmbito político brasileiro e, conseqüentemente, esquecidas do ponto de vista assistencial, prejudicando a saúde e o bem-estar de inúmeros brasileiros. 


\section{Resumo}

Este trabalho tem como objetivo discutir a moralidade do financiamento público das drogas órfãs, de altíssimo custo, para o tratamento de doenças genéticas raras, utilizando as ferramentas da Bioética, em especial o princípio da proteção, aplicável a indivíduos e populações vulneradas. Com base neste princípio, $e$ considerando o contexto normativo constituído pelo Sistema Único de Saúde (SUS), argumenta-se sobre a obrigação moral do Estado de prover políticas públicas que assistam ao indivíduo portador de uma doença genética - como a de depósito lisossômico - e que pode, portanto, ser considerado, "vulnerado", bem como são sugeridas medidas que possam implementar e dar sustentabilidade a tais políticas com ênfase em questões de alocação de recursos, focalização e equanimidade.

Doenças por Armazenamento dos Lisossomos; Medicamentos Excepcionais; Bioética

\section{Referências}

1. Drugs for rare diseases: mixed assessment in Europe. Prescrire Int 2007; 16:36-42.

2. Stolk P, Willemen MJC, Leufkens HGM. Rare essentials: drugs for rare diseases as essential medicines. Bull World Health Organ 2006; 84:745-51.

3. Dear JW, Lilitkarntakul P, Webb D. Are rare diseases still orphans or happily adopted? Br J Pharmacol 2006; 62:264-71.

4. Secretaria de Assistência à Saúde, Ministério da Saúde. Portaria SAS nº. 50. Diário Oficial da União 1995; 21 jun.

5. Ministério da Saúde. Portaria GM/MS nº. 2.305 . Aprova o Protocolo de Indicação de Tratamento Clínico da osteogenesis imperfecta com pamidronato dissódico no âmbito do Sistema Único de Saúde. Diário Oficial da União 2001; 19 dez.

6. Schramm FR, Kottow M. Principios bioéticos en salud pública: limitaciones y propuestas. Cad Saúde Pública 2001; 17:949-56.

7. Meikle PJ, Hopwood JJ. Newborn screening for lysosomal storage: current issues and approaches. Current Medical Literature 2005; 5:41-8.

\section{Colaboradores}

R. Boy concebeu e desenvolveu o tema, realizando a busca bibliográfica, discussão e redação do artigo. F. R. Schramm contribuiu com a discussão, redação e revisão do texto final de forma crítica e relevante.
8. Burrow TA, Hopkin RJ, Leslie ND, Tinkle BT, Grabowski GA. Enzyme reconstitution/replacement therapy for lysosomal storage diseases. Curr Opin Pediatr 2007; 19:628-35.

9. Gericke CA, Riesberg A, Busse R. Ethical issues in funding orphan drug research and development. J Med Ethics 2005; 31:164-8.

10. Hughes DA, Tunnage B, Yeo ST. Drugs for exceptionally rare diseases: do they deserve special status for funding? Q J Med 2005; 3:829-36.

11. Connock M, Juarez-Garcia A, Few E, Mans A, Dretzke J, Fry-Smith A, Moore D. A systematic review of the clinical effectiveness and cost-effectiveness of enzyme replacement therapies of Fabry disease and Mucopolysaccharidosis type I. Health Technol Assess 2006; 10:1-194.

12. Krug B, Schwartz I. Doença de Gaucher: delineando estratégias para promoção do uso racional de imiglucerase no Brasil. In: Anais do XVIII Congresso Brasileiro de Genética Clínica. Ribeirão Preto: Sociedade Brasileira de Genética Clínica; 2006. p. 58-9. 
13. Fórum da Reforma Sanitária na 13ạ Conferência Nacional de Saúde. http://www.idisa.org.br/site/ download/CEBES_Forum_Reforma_Sanitaria.pdf (acessado em Nov/2008).

14. Schramm FR. Bioética, economia e saúde: direito à assistência, justiça social, alocação de recursos. Rev Bras Cancerol 2000; 46:41-7.

15. Centro Brasileiro de Estudos em Saúde/Associação Brasileira de Economia da Saúde/ABRASCO/ Conselho Nacional de Secretários Municipais de Saúde/Associação Brasileira de Organização Não Governamental. Gasto em saúde no Brasil: é muito ou pouco? http://www.cebes.org.br/anexos/ GASTO\%20EM\%20SAUDE\%20NO\%20BRASIL.pdf (acessado em Nov/2008).

16. Schütz GE, Schramm FR. Alocação de recursos na assistência materno-infantil. In: Schramm RF, Braz M, organizadores. Bioética e saúde: novos tempos para mulheres e crianças. Rio de Janeiro: Editora Fiocruz; 2005 p. 105-23.

17. Beauchamp TL, Childress JF. Principles of biomedical ethics. Oxford: Oxford University Press; 2001.

18. Schramm RF. A saúde é um direito ou um dever? Rev Bras Bioética 2005; 2:187-200.

19. Kottow M. Bioética de proteção: considerações sobre o contexto latino-americano. In: Schramm FR, Rego S, Braz M, Palácios M, organizadores. Bioética: riscos e proteção. Rio de Janeiro: Editora Fiocruz; 2005. p. 1-44.

20. Ribeiro CDM, Schramm FR. Atenção médica, transplante de órgão e tecidos e políticas de focalização. Cad Saúde Pública 2006; 22:1945-53.

21. Schramm FR. Cuidados em saúde da mulher e da criança, proteção e autonomia. In: Schramm FR, Braz M, organizadores. Bioética e saúde: novos tempos para mulheres e crianças? Rio de Janeiro: Editora Fiocruz; 2005. p. 39-61.
22. Schramm FR. Bioética da proteção: justificativa e finalidades. Iatros 2005; 1:121-30.

23. Jonsen AR. Bentham in a box: technology assessment and health care allocation. Law Med Health Care 1986; 14:172-4.

24. Halliday JL, Collins VR, Aitken MA, Richards MPM, Olsson CA. Genetics and public health - evolution or revolution? J Epidemiol Community Health 2004; 58:894-9.

25. Horovitz DDG. Atenção aos defeitos congênitos no Brasil: propostas para estruturação e integração da abordagem no sistema de saúde [Tese de Doutorado]. Rio de Janeiro: Instituto de Medicina Social, Universidade do Estado do Rio de Janeiro; 2003.

26. Gross ML. Ethics, policy and rare genetic disorders: the case of Gaucher disease in Israel. Theor Med Bioeth 2002; 23:151-70.

27. Wraith JE, Scarpa M, Beck M, Bodamer OA, De Meirleir L, Guffon N, et al. Mucopolysaccharidosis type II (Hunter syndrome): a clinical review and recommendations for treatment in the era of enzyme replacement therapy. Eur J Pediatr 2008; 167:267-77.

28. Wraith JE, Hopwood JJ, Fuller M, Meikle PJ, Brooks DA. Laronidase treatment of mucopolysaccharidosis I. Biodrugs 2005; 19:1-7.

29. Wraith JE, Beck M, Lane R, van der Ploeg A, Shapiro E, Xue Y, et al. Enzyme replacement therapy in patients who have mucopolysaccharidosis I and are younger than 5 years; results of a multinational study of recombinant human alpha-L-iduronidase (laronidase). Pediatrics 2007; 120:e37-46.

Recebido em 15/Ago/2008

Vesão final reapresentada em 29/Dez/2008

Aprovado em 26/Jan/2009 